\title{
Methods for the Measurement of a Bacterial Enzyme Activity in Cell Lysates and Extracts
}

\author{
Brendan P. Burns ${ }^{1 *}$, George L. Mendz ${ }^{2}$, Stuart L. Hazell ${ }^{1}$ \\ ${ }^{1}$ School of Microbiology and Immunology and ${ }^{2}$ School of Biochemistry and Molecular Genetics, The \\ University of New South Wales, Sydney 2052, Australia. *To whom correspondence should be \\ addressed. E-mail: B.Burns@unsw.edu.au
}

\begin{abstract}
The kinetic characteristics and regulation of aspartate carbamoyltransferase activity were studied in lysates and cell extracts of Helicobacter pylori by three different methods. Nuclear magnetic resonance spectroscopy, radioactive tracer analysis, and spectrophotometry were employed in conjunction to identify the properties of the enzyme activity and to validate the results obtained with each assay. NMR spectroscopy was the most direct method to provide proof of ACTase activity; radioactive tracer analysis was the most sensitive technique and a microtitre-based colorimetric assay was the most costand time-efficient for large scale analyses. Freeze-thawing was adopted as the preferred method for cell lysis in studying enzyme activity in situ. This study showed the benefits of employing several different complementary methods to investigate bacterial enzyme activity.
\end{abstract}

\section{INTRODUCTION}

Studies of bacterial enzyme activities provide fundamental information relevant to microbial physiology, and to a more complete understanding of cell metabolism, bacterial evolution, and to the interactions that occurs between bacterium and host. Characterizing enzyme activities helps to elucidate regulatory mechanisms and pathways in an organism, and to identify proteins essential for cell survival. The ability to investigate enzyme activities in whole cell lysates or crude extracts is important for the initial identification of a particular activity, and for obtaining information on enzyme function in an environment close to the cellular milieu.

The activities of enzymes in the intracellular milieu depend on their intrinsic physico-chemical properties and on their interactions with other cellular components. Modulation of enzyme activities of functional relevance occurs not only among the constituents of recognised multienzyme clusters, but also among soluble enzymes and other cellular components $(1,2)$. Proteins have also been known to be more stable in concentrate than in dilute solutions (3). The basic mechanisms of action of soluble enzymes established in purified preparations are not expected to change from the in vivo conditions, however their activities are modulated by the intracellular milieu. Thus, in situ investigations of enzyme activities may reveal properties which would otherwise remain undetected.

(C1998 Biological Procedures Online. All rights reserved. Paper-based copying permitted for internal use for educational or non-profit purposes only. Otherwise, this article may be copied to paper provided that \$US15 per copy is paid directly to Biological Procedures Online, GMO 106 Box 44, Waterloo ON, Canada N2L 3G1. Electronic copying, storage or redistribution prohibited. ISSN 1480-9222 
The investigation of enzyme activity with a variety of methods results in synergies in the understanding of the characteristics of an enzyme. Application of different techniques can validate data obtained by one method by the results of the others, yield more specific information on a particular aspect of a system, and provide results in a range of assay conditions ordinarily not available to a single method. The benefits and disadvantages of particular techniques, such as sensitivity, efficiency, and cost, need to be considered to determine which are the most useful methods for a specific situation.

In a previous investigation (4), we used three different techniques to study aspartate carbamoyltransferase (ACTase) activity in Helicobacter pylori. This bacterium is an important human pathogen $(5,6)$, and the enzyme of interest is a key regulatory step in bacterial de novo pyrimidine nucleotide metabolism (7). As this enzyme appears to be essential for the survival of the bacterium, it provides a potential site for therapeutic intervention. Consequently, an in-depth understanding of the enzyme activity and regulation in situ would serve toward more rational design of therapeutic agents.

\section{METHODS}

\section{Preparation of cell free extracts}

Cells were grown at $37^{\circ} \mathrm{C}$ in an atmosphere of $10 \% \mathrm{CO}_{2}$ in air, and $95 \%$ humidity. Bacteria were harvested during the late logarithmic growth phase from agar plates into $0.1 \mathrm{M}$ Tris buffer (pH 8.0). $H$. pylori cells change shape as cultures grow older. The bacteria have spiral-rod forms when they are in log phase, and this shape becomes spherical with the formation of coccoids which tend to aggregate in the stationary phase. Cultures on plates will produce cells of different ages, but based on the morphology of the bacteria, phase contrast microscopy allows easy determination of the predominant growth phase. Under our experimental conditions, inspection of cultures showed that at $24 \mathrm{~h}$ growth more than $95 \%$ of the cells were in the spiral-rod form, and after $72 \mathrm{~h}$ growth more than $95 \%$ of the cells were coccoids. It should be noted that the formation of coccoid aggregates poses a problem for the estimation of cell growth by spectrophotometry at $600 \mathrm{~nm}$. The number of scattering centres can decrease significantly upon aggregation, and the measurements could underestimate bacterial growth.

Harvested cells suspended in Tris buffer were centrifuged at $17,000 \mathrm{~g}$ for $8 \mathrm{~min}$ at $4^{\circ} \mathrm{C}$. The resulting pellet was washed twice and resuspended in the same buffer. Cells were lysed by twice freezing in liquid nitrogen and thawing the suspensions, which were allowed to thaw completely before re-freezing. To obtain crude extracts, the lysates were centrifuged at $27,000 \mathrm{~g}$ for $8 \mathrm{~min}$ at $4^{\circ} \mathrm{C}$, and the supernatant carefully separated from the pellet made up of cell-envelope debris. The lysates and the crude extracts could be stored at $-20^{\circ} \mathrm{C}$ for several months without loss of activity.

\section{Measurement of ACTase activity}

Nuclear magnetic resonance spectroscopy (NMR). The unique potential of NMR spectroscopy for monitoring simultaneously the concentrations of several metabolites in complex milieux makes it one of the most powerful techniques available to carry out this type of study. 
For NMR measurements, lysates or cell-free extracts were resuspended in $0.15 \mathrm{M} \mathrm{NaCl}$ constituted in 5:1 $\mathrm{H}_{2} \mathrm{O} /{ }^{2} \mathrm{H}_{2} \mathrm{O}$ buffer mixtures to provide deuterium frequency lock for the spectrometer. Substrate concentrations were $40 \mathrm{mM}$ L-aspartate and $50 \mathrm{mM}$ carbamoyl phosphate, in 0.1 M HEPES buffer (pH 8.0). The reaction was started by adding $100 \mu \mathrm{l}$ of cell free extract to a total sample volume of $600 \mu 1$. To allow for efficient dispensing of the assay mixture into the $5 \mathrm{~mm}$ narrow bore NMR tube (Wilmad, Buena, NJ), the lysate or extract suspension and the substrates were mixed in an Eppendorf tube; diluting viscous cell lysates helped to place them into the tube.

Free induction decays were collected using a Bruker AM-500 spectrometer, operating in the Fourier transformation mode. Measurements were carried out at $37^{\circ} \mathrm{C}$, and sequential spectra were acquired automatically at $500.11 \mathrm{MHz}$ with presaturation of the water resonance. The instrumental parameters were: spectral width $5347 \mathrm{~Hz}$, memory size $8 \mathrm{~K}$, recycling time $3.5 \mathrm{~s}$, number of transients 144, and pulse angle $50^{\circ}(8 \mu \mathrm{s})$. To improve signal-to-noise, exponential filtering of $1 \mathrm{~Hz}$ was applied prior to Fourier transformation. Depending on the viscosity of the sample and the concentrations of the substrates, it is often advisable to employ resolution-enhancing window functions at the expense of losing some signal intensity; for example, a Gaussian window function with typical parameters: $-1 \mathrm{~Hz}$ line broadening, and 0.19 Gaussian parameter.

The time evolution of the utilisation of substrates and appearance of product was followed by acquiring sequential spectra of the reactions. Progress curves were obtained by measuring the integrals of substrate and product resonances at each point in time. Maximal rates were calculated from good fits (correlation coefficients ${ }^{3} 0.99$ ) of the data to straight lines for $30 \mathrm{~min}$ of the reactions.

Radioactive tracer analysis. ACTase activity was also determined using a radioactive assay that measures the incorporation of $\left[{ }^{14} \mathrm{C}\right]$ carbamoyl phosphate into carbamoyl aspartate (8). Typical enzyme assay conditions were $40 \mathrm{mM}$ L-aspartate, $0.4 \mathrm{mM}$ carbamoyl phosphate containing $\left[{ }^{14} \mathrm{C}\right]$ carbamoyl phosphate $\left(0.1 \mu \mathrm{Ci} \mu\right.$ mole $\left.^{-1}\right)$, Tris buffer $(0.1 \mathrm{M}, \mathrm{pH} 8.0)$, and cell-free extract in a final volume of 200 $\mu 1$. The reaction was initiated by adding $10 \mu \mathrm{l}$ of cell-free extract, and incubated for $10 \mathrm{~min}$ at $37^{\circ} \mathrm{C}$ in a water bath. Reactions were terminated by adding $100 \mu \mathrm{l}$ of $3 \mathrm{M}$ formic acid and heating at $80^{\circ} \mathrm{C}$ for 6 min, during which time any unreacted $\left[{ }^{14} \mathrm{C}\right]$ carbamoyl phosphate decomposed into phosphate and carbon dioxide, and the label was evaporated as ${ }^{14} \mathrm{CO}_{2}$. Heating for 6 minutes was found to be the optimum; less time was insufficient for complete conversion to ${ }^{14} \mathrm{CO}_{2}$ of the unreacted $\left[{ }^{14} \mathrm{C}\right]$ carbamoyl phosphate, and longer times were unnecessary. Ten milliliters of scintillation fluid (2,5-diphenyloxazole/toluene; $0.5 \% \mathrm{w} / \mathrm{v})$ were added, and the radioactive decay measured on a Packard Tricarb scintillation counter (Packard Instrument Co., USA).

Spectrophotometry. A colorimetric measurement of carbamoyl aspartate production using a microtitre protocol was employed for kinetic studies of the enzyme reaction (9), and all measurements were performed in triplicate. The method was based on that of Prescott and Jones (10) which uses a monoxime and antipyrine colour reagent for the detection of CAA. Two parts antipyrine (5 g/l in 50\% $(\mathrm{v} / \mathrm{v})$ sulfuric acid) were mixed with 1 part monoxime $(8 \mathrm{~g} / \mathrm{l}$ in $5 \%(\mathrm{v} / \mathrm{v})$ acetic acid). The colour reagent 
was prepared immediately before use. Owing to the instability of carbamoyl phosphate (11), it is essential that solutions are prepared fresh before each reaction. The reaction mixture contained the same concentrations of substrates and buffer as described above but without the $\left[{ }^{14} \mathrm{C}\right]$ carbamoyl phosphate, in a final volume of $200 \mu \mathrm{l}$. To start the enzyme reaction $50 \mu \mathrm{l}$ of freshly prepared carbamoyl phosphate was added to the wells, and the plate incubated for $10 \mathrm{~min}$ at $37^{\circ} \mathrm{C}$. One hundred microlitres of the color reagent was then added to each well to stop the reaction, and the plate incubated in the dark in a water bath at $60^{\circ} \mathrm{C}$ for $2 \mathrm{~h}$. Else and co-workers (9) recommend covering the plate with adhesive film while incubating; however when this was done water droplets would sometimes form on the underside of the film and mix into the wells. To avoid this problem another microtitre plate was used as a cover. The plate was then allowed to cool to room temperature in the dark for 15 minutes, and the absorbance measured at $450 \mathrm{~nm}$.

This method was adapted in the present study to provide an activity stain for ACTase in native PAGE gels. Native proteins were separated by modifying the procedure of Laemmli (12), where gel electrophoresis was performed under non-reducing and non-denaturing conditions. The gel was then sliced into $1 \mathrm{~mm}$ sections, and each section placed into a microtitre well containing the substrates of the ACTase reaction. An identical lane of electrophoretically separated proteins were also sliced and then incubated without aspartate, as a negative control. The microtitre plate was then processed as before.

\section{RESULTS AND DISCUSSION}

\section{ACTase activity and cellular localisation}

ACTase activity could be localised to the soluble fraction obtained by freeze-thawing cell suspensions and separating the cell envelope and cytosolic fractions by high-speed centrifugation. The use of freezethawing as a technique of cell lysis has several advantages over other methods in the study of enzyme activities. Sonication may not be desirable on account of the heat generated at the tip of the probe, that could result in denaturation of proteins. It has also been shown that sonication gives rise to $\mathrm{H}^{\circ}$ and $\mathrm{OH}^{\circ}$ radicals which can lead to protein fragmentation (13). Similarly, chemical lysis may affect enzyme activity detrimentally by disrupting enzyme complexes, etc. Some techniques, such as sonication and rupturing with glass beads, employ relatively harsh disruption procedures whose action may dislodge membrane-associated proteins, and thus yield positive activity in the soluble fraction. Freeze-thawing is an efficient and relatively 'gentle' process of cell disruption, which appears to open holes in the cell envelope and have minimal effects on its overall integrity, ensuring little shearing of membrane-bound proteins and good recovery of soluble proteins $(14,15)$. It is important when lysing cells to take into account not only the efficiency of the lysis procedure in breaking open the cells, but also of any effects the method may have on processes one may subsequently wish to study. For these reasons freezethawing was adopted as the preferred method for producing cell free extracts for studying ACTase activity in $H$. pylori.

\section{Different enzyme assays for ACTase study in H. pylori}

ACTase properties were studied in situ in cell-free extracts to obtain information on enzyme function in an environment that was closer to the bacterium's physiological conditions. There are numerous and 
unique advantages in studying enzyme activities in purified preparations, but the use of simpler milieux may mask properties such as protein-protein interactions, that could be observed in more complex conditions. Investigation of an enzyme activity in crude extracts allows for its characterisation, and at the same time retains the possibility of discovering some of its interactions with other cell components.

Three different methods of studying ACTase activity were employed in this investigation. The results obtained by each technique were compared with the data from the others, to validate them and/or gather additional information. Comparison of the rates in Table 1, indicated that each method represented a valid procedure for studying ACTase activity in $H$. pylori.

Table 1. Comparison of ACTase activity determined by three different methods

\begin{tabular}{cc}
\hline Assay method & ACTase activity $\left(\mu\right.$ mole $\left.\min ^{-1} \mathrm{mg}_{\text {protein }}^{-1}\right)$ \\
\hline NMR spectroscopy & $0.228 \pm .029$ \\
Radioactive tracer analysis & $0.256 \pm .023$ \\
Spectrophotometry & $0.272 \pm .024$ \\
\hline
\end{tabular}

NMR spectroscopy was the first method employed to identify ACTase in H. pylori. ${ }^{1} \mathrm{H}-\mathrm{NMR}$ spectra showing the time-course of substrates and products of the ACTase reaction in incubations with $\mathrm{H}$. pylori cell-free extracts were given in Figure 1 of the original article (1). Decrease of the peaks of the aspartate substrate, and appearance of peaks corresponding to a metabolic product were observed. The protons of the substrate carbamoyl phosphate are in chemical exchange with those of the aqueous solvent at rates which render them invisible in the ${ }^{1} \mathrm{H}-\mathrm{NMR}$ spectrum under the experimental conditions employed. The ${ }^{1} \mathrm{H}-\mathrm{NMR}$ resonances arising from $H$. pylori lysates or cell-free extracts were very small compared to those of the aspartate and the product, thus it was possible to follow the evolution of these metabolites over time. Assignment of the resonances from the product carbamoyl aspartate (CAA) was achieved by adding this metabolite to assay mixtures and comparing the spectral position of its resonances with those of the product in the bacterial preparations.

Metabolites have NMR spectral signatures characterized by their chemical structures. In the case of CAA the resonances arising from $\alpha-\mathrm{CH}$ and $\beta-\mathrm{CH}_{2}$ groups of the aspartate moiety have chemical shifts and coupling constants different from those of the amino acid aspartate. Thus, it was possible to make an unambiguous assignment of CAA. This definite identification of a reaction product, is a feature lacking in other enzyme assays, particularly when complex preparations are assayed. For example, the radioactive or colorimetric assay measures the formation of $a$ radioactive product and $a$ ureido product, respectively, without yielding sufficient information about its identity. Although proper controls could ensure the validity of these methods, NMR spectroscopy gave direct evidence for the presence of ACTase activity. However, this technique has limitations, some of which are: a) sensitivity, because often relatively high concentrations of substrates are needed to obtain clear NMR signals; b) spectral overlap, under certain conditions some peaks may appear superimposed on others thus masking specific effects; and c) cost of operating NMR spectrometers, which may preclude their use in large scale enzyme analysis. Notwithstanding its limitations, this technique has proven most effective in the study of enzyme characteristics in $H$. pylori $(4,16-18)$.

Radioactive tracer analysis was another useful method to study ACTase activity in cell-free extracts. A 
main advantage of this technique is its sensitivity; measurement of radioactive decays allowed for determination of ACTase activity at relatively small enzyme concentrations. This could prove especially useful in studies on purified proteins, where yield is often quite low. Radioactive tracer analyses provided information on ACTase activity that could not be obtained by NMR analysis or the colorimetric assay. Specifically, to study the effects of carbamoyl aspartate, the ACTase end-product, on enzyme activity. In these experiments the added exogenous CAA will mask the product formed through the activity of the enzyme in both the NMR and colorimetric assays; the higher the concentration of added CAA, the less accurate are the measurements of the activity of the enzyme by NMR spectroscopy or spectrophotometry. The effects of CAA on ACTase activity were assessed confidently employing radioactive tracer analysis and, as shown in Figure 1, the observed product-inhibition of the enzyme activity was consistent with the inhibitory effects CAA had on $H$. pylori growth.

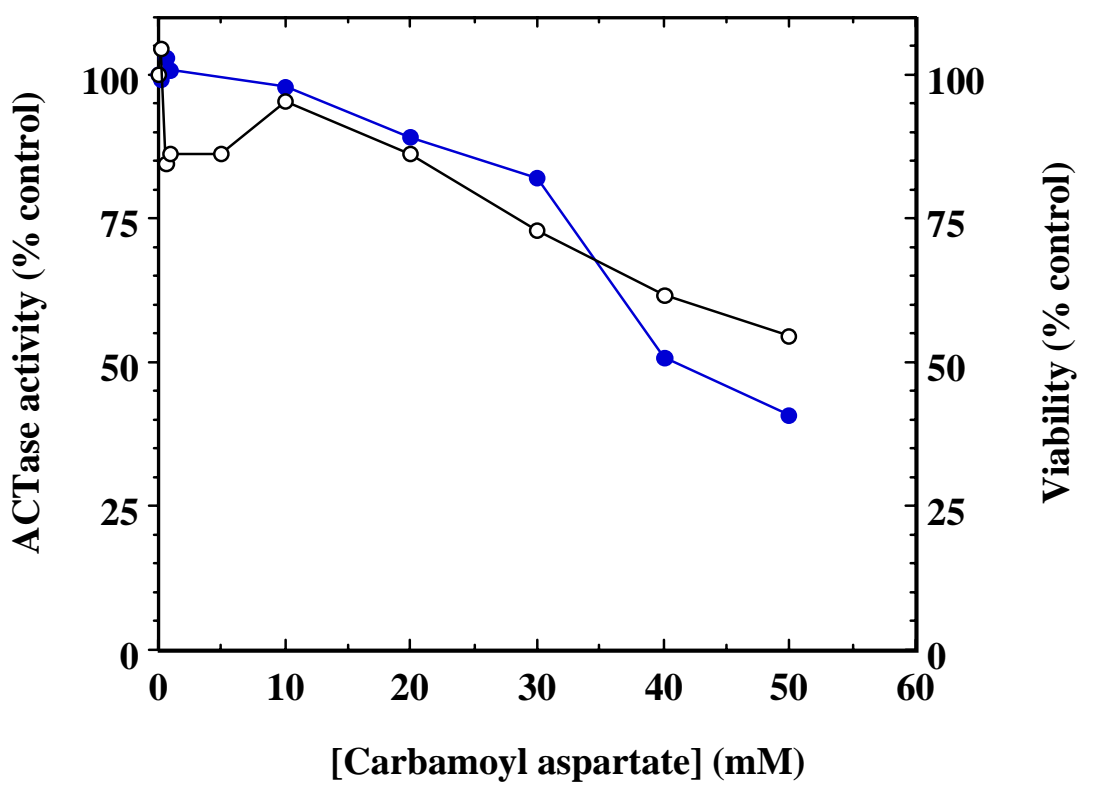

Figure 1. Effects of carbamoyl aspartate (CAA) on ACTase activity and viability of H. pylori. The activity or viability are taken as $100 \%$ in the absence of CAA. (•) ACTase activity; $(\xi) \square$ H. pylori viability.

Because the labelled carbamoyl phosphate is used only in trace amounts and is an unstable compound it is very important to monitor its purity continuously. At one point in the work, significant radioactive counts were measured in samples only containing $\left[{ }^{14} \mathrm{C}\right]$ carbamoyl phosphate, even after addition of strong acid and heating. As mentioned in the methods, this treatment should allow for the removal of any unreacted $\left[{ }^{14} \mathrm{C}\right]$ carbamoyl phosphate as ${ }^{14} \mathrm{CO}_{2}$. The finding indicated the presence of an acid-stable contaminant in the stock $\left[{ }^{14} \mathrm{C}\right]$ carbamoyl phosphate. Apart from the obvious expense in obtaining fresh radioactive substrate, the possibility of further contamination and false positive results suggested this method may not the most appropriate for large scale characterisation of ACTase activity. Another less technical disadvantage of this technique is the safety in the handling of radioactive products. Although 
due care should prevent any problems, the element of risk involved may favour the use of a technique with less hazardous materials.

The use of a micro-titre based colorimetric assay provided a third method for the study of ACTase activity, and the most useful for large scale measurements. The method was essentially as described previously (9), but several findings proved useful in optimising the assay for this work. Although the authors suggest that the colour development reagents can be stored for a short period of time (10), it was found in the present study that the most consistent results were obtained when the reagents were made fresh immediately prior to use. In constructing the CAA standard curve in Figure 2, it was found that the absorbance values increased linearly with respect to CAA up to $0.15 \mu$ mole CAA, slightly more than the $0.125 \mu$ mole reported previously. At CAA quantities higher than this, the readings suffered from noise and were no longer linear with respect to CAA. This was important in assessing that this technique could not be used to study the effects of CAA on ACTase activity, as described above. For CAA quantities below $0.015 \mu$ mole, the readings were below the limits of sensitivity of the assay. Comparison of colour development times between 2 and $7 \mathrm{~h}$, revealed that a two hour development time yielded the most consistent and reproducible results.

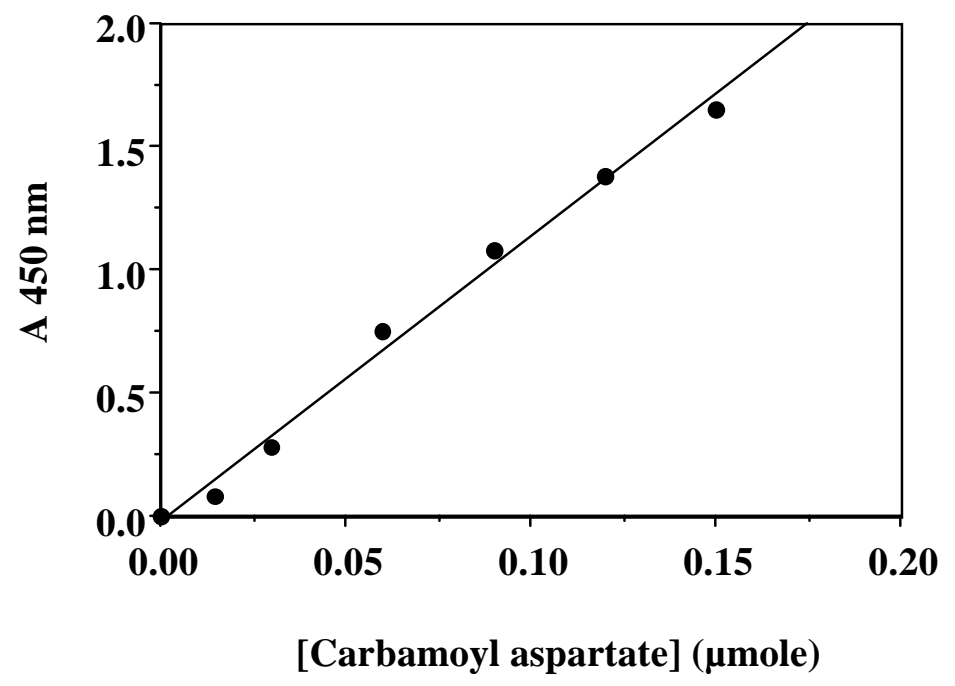

Figure 2. Measurement of carbamoyl aspartate employing the microtitre assay.

The colorimetric assay was adopted as the preferred method, because its protocol was the more efficient and inexpensive. Employing this assay, several 96-well plates could be used, allowing for the processing of hundreds of samples simultaneously. Experiments could be performed routinely in at least triplicate, increasing their precision. The colorimetric technique provided significant efficiency improvements compared with the processing time of both NMR and the radioactive analysis methods. A novel adaptation of this technique was also seen with the use of this method to detect ACTase activity in a native PAGE gel. A single area of ACTase activity was localised approximately $8 \mathrm{~mm}$ down on a $6 \%$ 
alcrylamide gel (Figure 3), suggesting the presence of a high molecular weight protein. This modification of this microtitre assay for use as an enzyme activity stain may be prove useful particularly for protein isolation and purification.

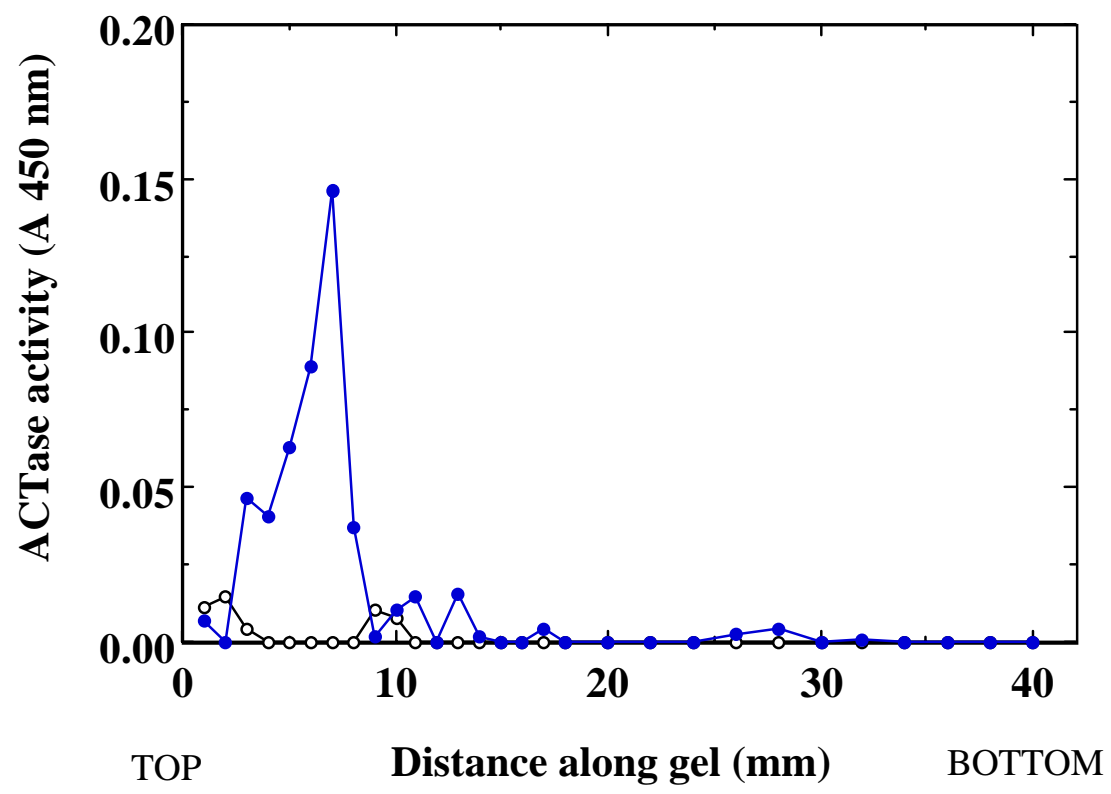

Figure 3. ACTase activity stain. Profile of ACTase activity of $1 \mathrm{~mm}$ sections of a $6 \%$ native PAGE gel of electrophoretically separated $H$. pylori proteins. - Sections incubated with carbamoyl phosphate and aspartate; $\xi$ Sections incubated with carbamoyl phosphate alone.

The ability to include a good number of controls in the measurements also ensured very reliable measurements of ACTase activity. No significant increase in optical density was observed between controls with only enzyme extracts and samples with enzyme extracts together with one of the substrates, suggesting there was little or no formation of ureido products other than carbamoyl aspartate. No increase in optical density was observed when carbamoyl phosphate and aspartate were incubated without cell-free extracts, suggesting that any chemical formation of carbamoyl aspartate was below the detection limits of the method. Table II is a summary of the results on ACTase activity using this method, showing the significant data generated using this technique.

Table II. Summary of ACTase activity characteristics in H. pylori

\begin{tabular}{cc}
\hline Enzyme characteristic & Data from $H$. pylori ACTase \\
\hline$K_{\mathrm{m}}($ carbamoyl phosphate $)$ & $0.6 \mathrm{mM}$ \\
$K_{\mathrm{m}}(\mathrm{L}$-aspartate $)$ & $11.6 \mathrm{mM}$
\end{tabular}

Biological Procedures Online • Vol. 1 No. $1 \bullet$ May 14, $1998 \bullet$ www.biologicalprocedures.com 


\begin{tabular}{|c|c|}
\hline Enzyme characteristic & Data from $H$. pylori ACTase \\
\hline$V_{\max }$ (carbamoyl phosphate) & $0.68 \mu$ mole $\min ^{-1}(\mathrm{mg} \text { protein })^{-1}$ \\
\hline$V_{\max }($ L-aspartate $)$ & $0.64 \mu$ mole $\min ^{-1}(\mathrm{mg} \text { protein })^{-1}$ \\
\hline pH optimum & 8.0 \\
\hline Temperature optimum & $45^{\circ} \mathrm{C}$ \\
\hline Substrate specificity & Specific for L-aspartate \\
\hline Effect of aspartate analogues & Succinate and malate inhibit \\
\hline Effect of phosphate analogues & Phosphonoacetate and acetyl phosphate inhibit \\
\hline Effect of PALA & $50 \%$ inhibition at $0.1 \mu \mathrm{M} ; K_{\mathrm{i}}$ of $0.245 \mu \mathrm{M}$ \\
\hline Effect of nucleotides & $\begin{array}{c}\text { All, tri-, di-, and monophosphate nucleotides } \\
\text { inhibit }\end{array}$ \\
\hline
\end{tabular}

The main limitation found with the colorimetric assay was already described, namely the inability to study the effect of the end-product CAA on enzyme activity. Lack of results in detecting ACTase activity in whole cells was thought to be another limitation of the method. However, the finding that $\left[{ }^{14} \mathrm{C}\right]$ carbamoyl phosphate was not transported into the cells, indicated that the lack of detection of enzyme activity in whole cells was a feature of the permeability of the $H$. pylori cell membrane, and not a deficiency of the colorimetric assay.

In conclusion, this study has demonstrated the benefits of using several enzyme assays to investigate in situ the functioning of the ACTase enzyme in $H$. pylori. The use of a direct NMR method, a sensitive radioactive assay, and a very efficient micro-titre assay allowed for a comprehensive understanding of this activity in a complex background. Further use of such a combination of methods should allow for more complete understandings of bacterial enzyme systems in situ.

\section{REFERENCES}

1. Stryer, L. 1988. Biochemistry (3rd Ed). W.H. Freeman \& Co: New York.

2. Jost, P.C., and Griffith O.H. 1982. Lipid-protein interactions. Vol 1. John Wiley \& Sons: New York.

3. Coakley, W., Brown, R.C., and James, C.J. 1973. The inactivation of enzymes by ultrasonic cavitation at $20 \mathrm{kHz}$. Arch. Biochim. Biophys 159, 722-729.

4. Burns, B.P., Hazell S.L., and Mendz, G.L. 1997. In situ properties of aspartate carbamoyltransferase activity in Helicobacter pylori. Arch. Biochem. Biophys. 347, 119-125.

5. IARC. 1994. Schistosomes, liver fluke and Helicobacter pylori. Abst. IARC Monographs on the Evaluation of Carcinogenic Risks to Humans, vol. 61, pp. 177-240. Lyon: International Agency for Research on Cancer, World Health Organisation.

6. Lee, A., Fox, J., and Hazell, S. 1993. Pathogenicity of Helicobacter pylori: a perspective. Infect. Immun. 61, 1601-1610.

7. Gerhart, J. C., and Pardee, A. B. 1962. The enzymology of control by feedback inhibition. $J$. Biol. Chem. 237, 891-896.

8. Mori, M., Ishida, H., and Tatibana, M. 1975. Aggregation and catalytic properties of the 
multienzyme complex catalyzing the initial steps of pyrimidine biosynthesis in rat liver. Biochemistry 14, 2622-2630.

9. Else, A. J., and Hervé, G. 1990. A microtitre plate assay for aspartate transcarbamylase. Anal. Biochem. 186, 219-221.

10. Prescott, L. M., and Jones, M. E. 1969. Modified methods for the determination of carbamoyl aspartate. Anal. Biochem. 32, 408-419.

11. Allen, C. M., and Jones, M. E. 1964. Decomposition of carbamoyl phosphate in aqueous solutions. Biochemistry 3, 1238-1247.

12. Laemmli, U.K. 1970. Cleavage of structural proteins during the assembly of the head of bacteriophage T4. Nature 227, 680-685.

13. Lopez, P. and Burgos, J. 1995. Lipoxygenase inactivation by manothermosonication: effects of sonication physical parameters, $\mathrm{pH}, \mathrm{KCl}$, sugars, glycerol, and enzyme concentration. J. Agric. Food Chem. 43, 620-625.

14. Furth, A.J. 1975. Purification and properties of a constitutive $\beta$-lactamase from Pseudomonas aeruginosa strain dalgleish. Bioch. Biophys. Acta. 377, 431-443.

15. Diffley, P. and Jayawardena, A.N. 1982. Comparitive analysis of procedures used to isolate variant antigen from Trypanosoma brucei rhodesien. J. Parasitol. 68, 532-537.

16. Mendz, G. L., Jimenez, B. M., Hazell, S. L., Gero, A. M., and O'Sullivan, W. J. 1994. De novo synthesis of pyrimidine nucleotides by Helicobacter pylori. J. App. Bacteriol. 77, 1-8.

17. Mendz, G.L., Hazell, S.L. and Burns, B.P. 1994. Evidence for the Entner-Duodoroff Pathway in Helicobacter pylori . Arch. Biochem. Biophys. 312, 349-356.

18. Burns, B.P., Hazell, S.L. and Mendz, G.L. 1995. Acetyl Coenzyme A carboxylase Activity in Helicobacter pylori and the requirement of increased carbon dioxide for growth. Microbiology 141, 3113-3118. 